\title{
Landsat Time Series Analysis of Vegetation Changes in Solar Energy Development Areas of the Lower Colorado Desert, Southern California
}

\author{
Christopher Potter \\ CASA Systems 2100, Los Gatos, California, USA \\ Email: info@casa2100.com
}

Received 28 December 2015; accepted 10 January 2016; published 2 February 2016

Copyright (C) 2016 by author and Scientific Research Publishing Inc.

This work is licensed under the Creative Commons Attribution International License (CC BY). http://creativecommons.org/licenses/by/4.0/

(c) (i) Open Access

\begin{abstract}
Land cover change from renewable energy development in southern California is receiving increasing attention due to potential impacts on protected area conservation, endangered species, and greenhouse gas emissions. This study was designed to quantify and map, for the first time, variations desert vegetation canopy density and related growth rates using $\mathbf{3 0}$ consecutive years of Landsat satellite image data across the Lower Colorado Desert. The time-series for mean normalized difference vegetation index (NDVI) values sampled from each of the three major land cover types (shrubland, barren sand dune, and developed urban) showed no significant positive or negative trend in vegetation canopy density. Three periods of significant decrease in NDVI were detected during the drought periods of 1989-1990, 2002-2003, and 2013-2015, indicating that annual precipitation has been the main controller of shrubland canopy growth and green cover. Shrubland canopy cover has been relatively stable in renewable energy development zones since the mid-2000s. NDVI change in the period after nearly all southern California solar energy developments were initiated (post-2010) could be attributed largely to topographic water flow pathways through canyons and desert washes, both in and around all solar energy development zones.
\end{abstract}

\section{Keywords}

Landsat, Shrubland, Solar Energy Development, Lower Colorado Desert, DRECP

\section{Introduction}

Damage to native shrubland vegetation in southern California resulting from solar energy development projects

How to cite this paper: Potter, C. (2016) Landsat Time Series Analysis of Vegetation Changes in Solar Energy Development Areas of the Lower Colorado Desert, Southern California. Journal of Geoscience and Environment Protection, 4, 1-6. 
has been speculated to cause negative impacts on biodiversity conservation and greenhouse gas emissions from the disturbance or destruction of desert plant biomass and surface soils [1]-[3]. Renewable energy development projects sited near protected areas (e.g., state and national parks) have been suspected of disrupting dispersion capabilities of native species and facilitating invasions of non-native species through habitat loss, fragmentation, and isolation [2]. These same assessment reports [2] [3] have called for, but have not included, rigorous statistical analyses that could quantify both internal and external threats to protected southern California desert ecosystems, as required for assessing vulnerability of landscape sustainability.

The objective of this remote sensing data analysis for southern California deserts was to quantify and characterize, for the first time, variations desert vegetation canopy density and related growth rates using 30 consecutive years of Landsat satellite image data across the Lower Colorado Desert region (Figure 1). The normalized difference vegetation index (NDVI) from Landsat has been closely correlated with percent cover measurements of green vegetation canopies in arid eco-systems, as reported in numerous published studies [4]-[10]. More specifically, reference [11] found that NDVI from Landsat was tightly correlated $(r=0.88 ; p<0.05)$ with total percent cover of live vegetation in a semi-arid sagebrush ecosystem in south-central Utah. Reference [12] reported similar results for NDVI correlations with fractional cover in creosote-dominated shrubland sites of New Mexico.

The Desert Renewable Energy Conservation Plan [13] (DRECP) has become a major component of the State of California Renewables Portfolio Standard. The DRECP is intended to provide effective environmental protections and natural resource conservation of desert ecosystems as appropriate development of renewable energy projects advances in southern California. The DRECP covers parts of seven California counties: Imperial, Inyo, Kern, Los Angeles, Riverside, San Bernardino, and San Diego. Approximately 91,000 km² of federal and nonfederal California desert land are part of the DRECP Area. By the end of 2016, the Final DRECP Environment Impact Statement (EIS) will be completed for public lands under agency jurisdictions within the DRECP area, including numerous zones designated as Development Focus Areas (DFAs), as shown in Figure 1.

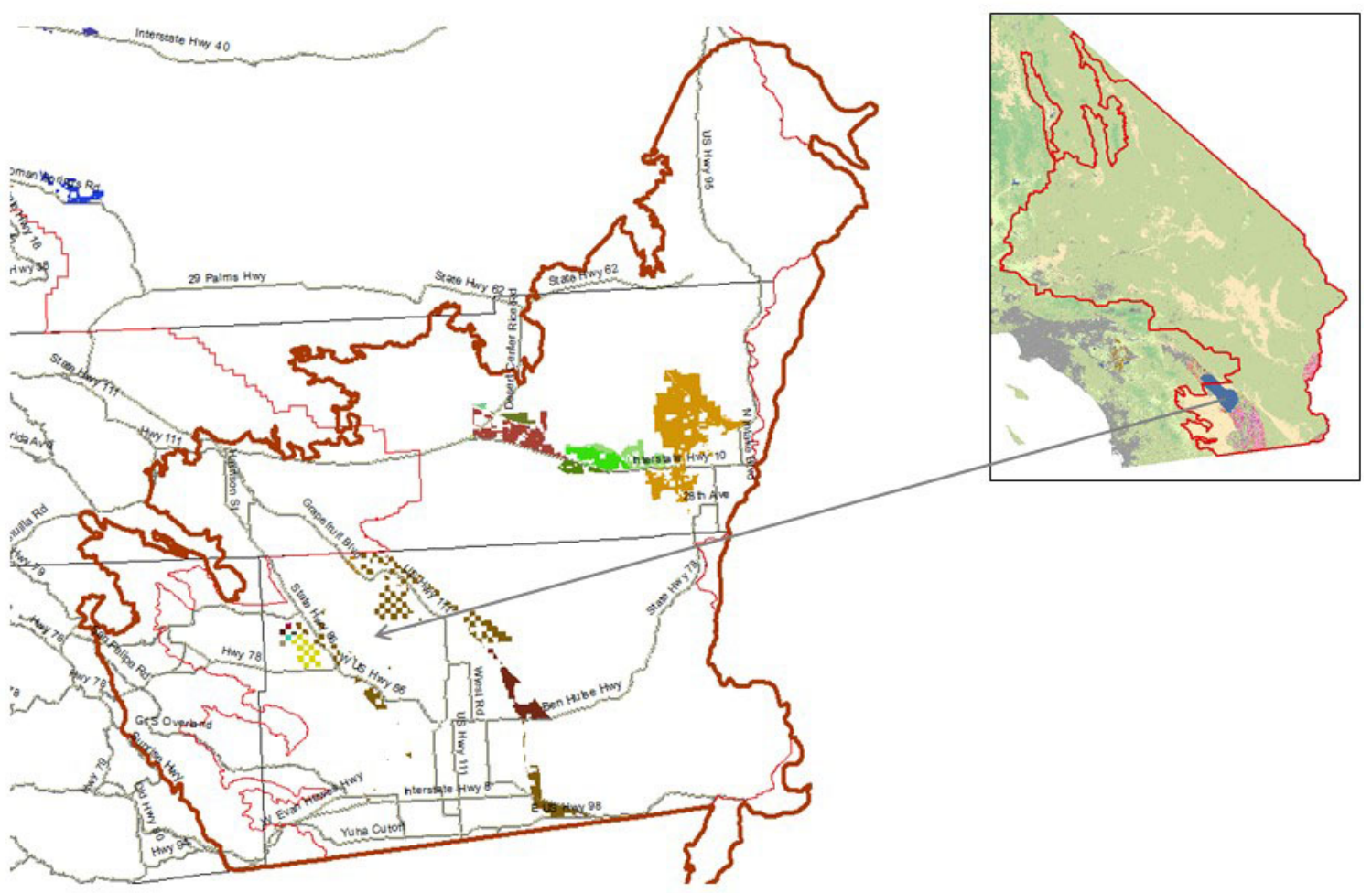

Figure 1. Map of the lower Colorado Desert (brown line) and DRECP (red line) study area, with development focus areas (DFAs) in other shaded polygon outlines. Smaller map in the right panel shows vegetation cover types for the entire DRECP area, with shrublands in light green, barren sand dunes in tan, developed urban areas in grey, croplands in magenta, and open water in blue. 


\section{Study Area}

The area of interest for this Landsat data study of vegetation cover growth within the southern DRECP region was the Lower Colorado Desert of California (Figure 1). This area is bounded on the west by the Laguna, Santa Rosa, and San Jacinto mountain ranges, on the east by the California-Arizona state line, on the north by the gradual transition to the Mojave Desert, and on the south by the California-Mexico border [14]. Low annual rainfall (50 - $300 \mathrm{~mm}$ ) and high temperatures (reaching $45^{\circ} \mathrm{C}$ in the summer) make this area one of the most arid in North America. Vegetation communities in the Colorado Desert have been classified into seven basic types: creosote bush scrub, cactus scrub, saltbush scrub, alkali sink, microphyll woodland, psammaophytic scrub, and palm oasis [15].

\section{Methods}

For this study, near cloud-free imagery from the Landsat sensor was selected from the United States Geological Survey (USGS) Earth Explorer data portal (available online at earthexplorer.usgs.gov) for every year from 1985 to 2015. Landsat scenes from path/row 39/37 were acquired between April 1 and May 30 each year, around the peak flowering period in the Lower Colorado Desert growing season [15]. All images used in this study were geometrically registered (UTM Zone 10) using terrain correction algorithms (Level 1T) applied by the USGS EROS Data Center.

For the Landsat 4 - 5 Thematic Mapper (TM) images acquired between 1985 and 2011, 30-m resolution surface reflectance data were generated from the Landsat Ecosystem Disturbance Adaptive Processing System [16]. Moderate Resolution Imaging Spectroradiometer (MODIS) atmospheric correction routines were applied to Level-1 TM data products. Water vapor, ozone, geopotential height, aerosol optical thickness, and digital elevation are input with Landsat data to the Second Simulation of a Satellite Signal in the Solar Spectrum (6S) radiative transfer models to generate top of atmosphere (TOA) reflectance, surface reflectance, brightness temperature, and masks for clouds, cloud shadows, adjacent clouds, land, snow, ice, and water. Landsat 8 (after 2012) surface reflectance products were generated from the L8SR algorithm, a method that uses the scene center for the sun angle calculation and then hard-codes the view zenith angle to 0 . The solar zenith and view zenith angles are used for calculations as part of the atmospheric correction.

NDVI was computed for this study using Landsat bands as:

$$
\text { NDVI }=(\text { NIR }- \text { Red }) /(\text { NIR }+ \text { Red })
$$

where Red is the reflectance from 0.63 to $0.69 \mu \mathrm{m}$ and NIR is the near-infrared reflectance from 0.77 to $0.90 \mu \mathrm{m}$ [17]. NDVI was scaled from 0 to 10,000, with low values of (near 0) indicating barren land cover and high values of NDVI (above 7000) indicating dense canopy vegetation cover [18].

Land cover types for the study area were determined based on the National Agricultural Statistics Service (NASS), California Cropland Data Layer (CDL) from 2014 (available online at nassgeodata.gmu.edu/CropScape). The CDL is a raster, geo-referenced land cover data layer with a ground resolution of 30 m produced using satellite imagery from the Landsat sensor collected during the summer season. Elevation, slope, and aspect were determined at $30 \mathrm{~m}$ spatial resolution from the USGS National Elevation Dataset (NED).

Calculations of statistical significance of trends over time were computed to test the hypothesis of chance deviations from a flat trend, following the same analysis approach applied by reference [19]. A 95\% confidence interval for a yearly sample mean difference was reported as greater than (plus or minus) 2 standard errors (SE) of the mean (at $p<0.05$ ) [20]. Within each of the three major land cover types of the region (shrublands, barren sand dunes, and developed urban areas), 2000 point locations were randomly selected for statistical summaries and comparisons of yearly mean NDVI values.

\section{Results and Discussion}

Resulting plots of that the complete 30-year time-series for mean NDVI sampled from each of the three major land cover types showed no significant positive or negative trends in vegetation canopy density since 1985 (Figure 2). There were, nonetheless, three notable periods of significant $(p<0.05)$ decrease in the mean annual NDVI from the 30-year NDVI averages (by vegetation type), namely during the droughts of 1989-1990, 20022003, and 2013-2015. Across all 30 years, 2 SE of the mean yearly NDVI sampled for shrubland cover varied 
between 20 and 40 NDVI units, whereas the three largest negative departures from the 30-year shrubland NDVI mean were between 300 and 500 NDVI units during these extreme drought periods in southern California (as also documented by reference [21]).

Comparisons of the three different cover types showed that developed urban and industrial locations had vegetation green cover at levels consistently 1000 NDVI higher than desert shrubland cover locations, which receive no watering by residential or commercial irrigation systems (Figure 2). Since the mid-1980s, mean yearly NDVI levels for shrubland cover within DFAs have been 200 and 500 NDVI units below shrubland cover outside of the DFAs, which indicates that the most productive shrubland cover in the Lower Colorado Desert has not yet been included within DFAs for solar energy development. As expected, barren sand dune covered locations showed the lowest mean NDVI levels and the lowest within-year variations across all years.

The spatial pattern of change in NDVI (Figure 3), starting from the period before solar energy developments

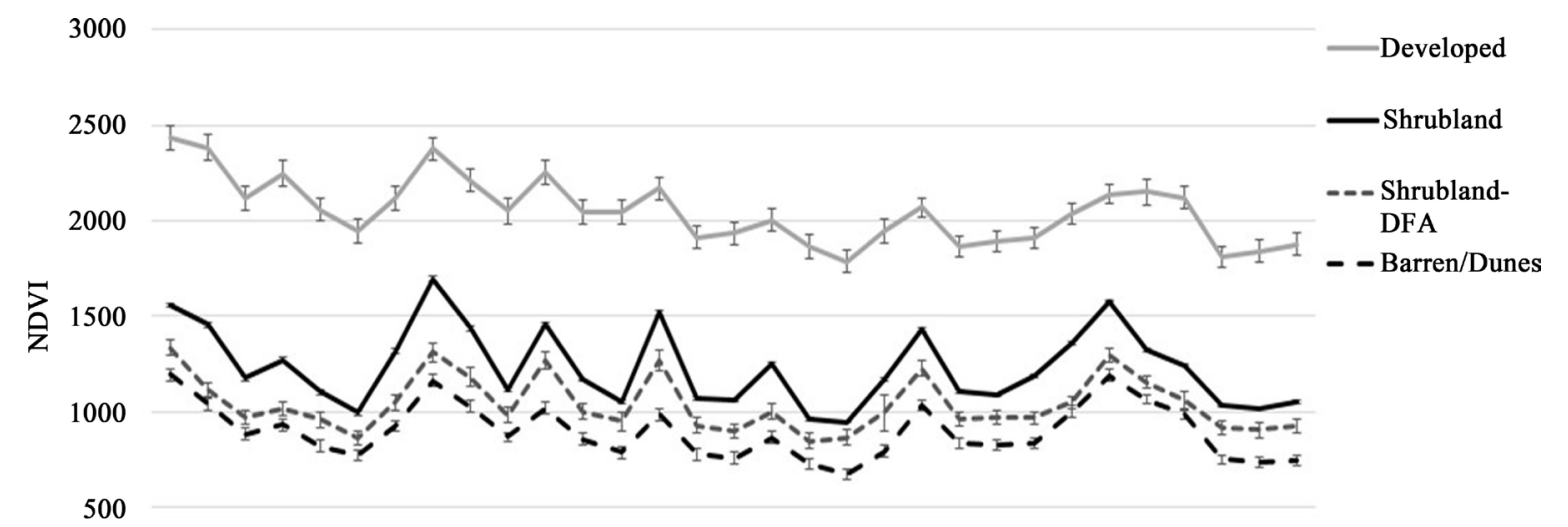

0

\section{ڤ \&}

Figure 2. Plot of the 30-year trend in Landsat NDVI for lower Colorado desert vegetation cover types. Error bars represent 2 SE of the yearly mean NDVI computed for 2000 randomly selected points within each vegetation cover type.

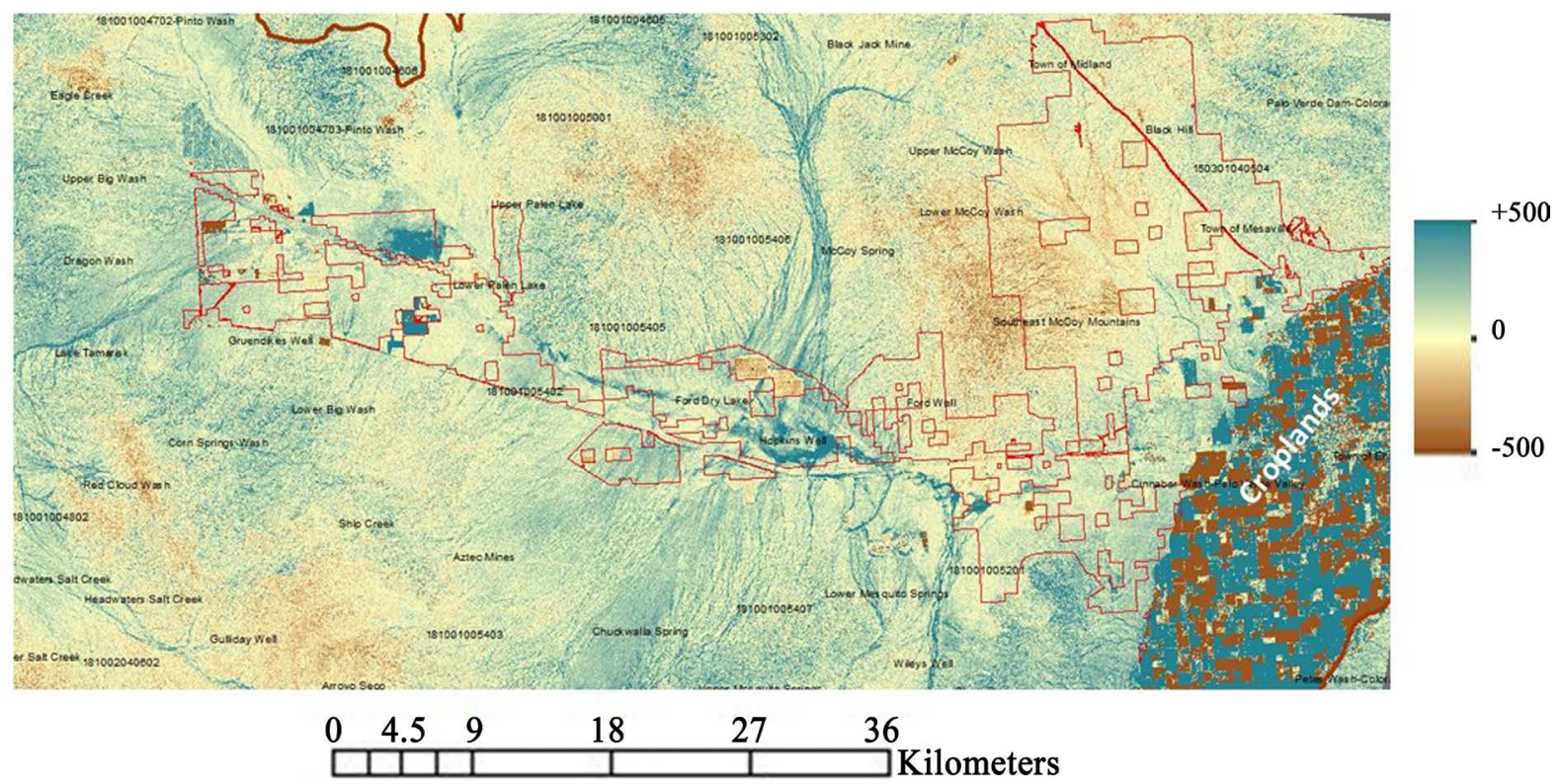

Figure 3. Map image of the change in Landsat NDVI between 2003 (prior to solar energy developments) and the present (2015) for East Riverside DFAs outlined in red. Positive changes indicate an increase in NDVI since 2003. Drainage basin names are included from Seaber et al. [22]. 
were initiated in the region to the present, showed that DFAs of East Riverside County were largely unchanged in vegetation canopy cover, or saw increases of between 200 and 400 NDVI units following river channels and desert washes, such as Ford Dry Lake, Lower Palen Valley, McCoy Wash, and Cinnabar Wash. The most conspicuous patterns of recent NDVI increase followed these well-delineated hydrologic drainage basins, all at lower than 200 meters elevation [22]. The only extensive areas near DFAs where NDVI recently decreased by between 200 and 400 units were located on steep slopes above 400 meters elevation in the McCoy and Palen Mountains where solar energy developments are not currently planned.

\section{Conclusions}

It can be concluded that inter-annual variations in precipitation accounted for nearly all the periodic changes in NDVI in shrubland communities observed since 1985 across the Lower Colorado Desert. There have been statistically significant decreases in shrubland cover to a stable baseline level of about 1000 NDVI units during each extreme drought period recorded over the past 30 years, followed by recovery to levels between 1500 and 2000 NDVI units during more favorable rainfall years. Hernandez et al. [2] reported that nearly 50\% of utility scale solar energy development (greater than 1 megawatt capacity) in California is being sited in shrubland and scrubland cover types, potentially leading to increased isolation of endangered species and non-native species invasions within these ecosystems.

However, results from analysis of Landsat NDVI 30-year trends and spatial patterns of change over the past decade do not support contentions that detectable disturbance of shrubland vegetation cover has yet resulted in adverse ecological impacts to communities of the Lower Colorado Desert region, either within DFAs of East Riverside County or in shrublands outside of the DFAs. Instead, shrubland canopy cover has been relatively stable since the mid-2000s. Subtle changes in NDVI in the period after nearly all southern California solar energy developments were initiated (post-2010, [2]) could be attributed largely to topographic water flow pathways through canyons and desert washes, both in and around the solar energy DFAs.

\section{References}

[1] Lovich, J.E. and Ennen, J.R. (2011) Wildlife Conservation and Solar Energy Development in the Desert Southwest, United States. Bioscience, 61, 982-992. http://dx.doi.org/10.1525/bio.2011.61.12.8

[2] Hernandez, R.R., Hoffacker, M.K., Murphy-Mariscal, M.L., Wu, G.C. and Allen, M.F. (2015a) Solar Energy Development Impacts on Land Cover Change and Protected Areas. Proceedings of the National Academy of Sciences, 112, 13579-13584.

[3] Hernandez, R.R., Hoffacker, M.K. and Field, C.B. (2015b) Efficient Use of Land to Meet Sustainable Energy Needs. Nature Climate Change, 5, 353-358. http://dx.doi.org/10.1038/nclimate2556

[4] Anderson, G.L., Hanson, J.D. and Haas, R.H. (1993) Evaluating Landsat Thematic Mapper Derived Vegetation Indices for Estimating above Ground Biomass on Semiarid Rangelands. Remote Sensing of Environment, 45, 165-175. http://dx.doi.org/10.1016/0034-4257(93)90040-5

[5] Pickup, G., Chewings, V.H. and Nelson, D.J. (1993) Estimating Changes in Vegetation Cover over Time in Arid Rangelands Using Landsat MSS Data. Remote Sensing of Environment, 43, 243-263. http://dx.doi.org/10.1016/0034-4257(93)90069-A

[6] O’Neill, A.L. (1996) Satellite-Derived Vegetation Indices Applied to Semiarid Shrub Lands in Australia. Australian Geographer, 27, 185.

[7] Elmore, A.J., Mustard, J.F., Manning, S.J. and Lobell, D.B. (2000) Quantifying Vegetation Change in Semiarid Environments: Precision and Accuracy of Spectral Mixture Analysis and the Normalized Difference Vegetation Index. Remote Sensing of Environment, 73, 87-102. http://dx.doi.org/10.1016/S0034-4257(00)00100-0

[8] Weiss, J.L., Gutzler, D.S., Coonrod, J.E.A. and Dahm, C.N. (2004) Long-Term Vegetation Monitoring with NDVI in a Diverse Semi-Arid Setting, Central New Mexico, USA. Journal of Arid Environments, 58, 249-272. http://dx.doi.org/10.1016/j.jaridenv.2003.07.001

[9] Huang, S., Potter, C., Crabtree, R.L., Hager, S. and Gross, P. (2010) Fusing Optical and Radar Data to Estimate Sagebrush, Herbaceous, and Bare Ground Cover in Yellowstone. Remote Sensing of Environment, 114, 251-264.

[10] Olexa, E.M. and Lawrence, R.L. (2014) Performance and Effects of Land Cover Type on Synthetic Surface Reflectance Data and NDVI Estimates for Assessment and Monitoring of Semi-Arid Rangeland. International Journal of Applied Earth Observation and Geoinformation, 30, 30-41. http://dx.doi.org/10.1016/j.jag.2014.01.008

[11] Ramsey, R.D., Wright Jr., D.L. and McGinty, C. (2004) Evaluating the Use of Landsat 30 m Enhanced Thematic 
Mapper to Monitor Vegetation Cover in Shrub-Steppe Environments. Geocarto International, 19, 39-47. http://dx.doi.org/10.1080/10106040408542305

[12] Montandon, L.M. and Small, E.E. (2008) The Impact of Soil Reflectance on the Quantification of the Green Vegetation Fraction from NDVI. Remote Sensing of Environment, 112, 1835-1845. http://dx.doi.org/10.1016/j.rse.2007.09.007

[13] DRECP (2010) Recommendations of Independent Science Advisors for the California Desert Renewable Energy Conservation Plan (DRECP). Prepared for Renewable Energy Action Team.

[14] Marks, J.B. (1950) Vegetation and Soil Relations in the Lower Colorado Desert. Ecology, 31, 176-193. http://dx.doi.org/10.2307/1932385

[15] Schoenherr, A.A. and Burk, J.H. (2007) Colorado Desert Vegetation. In: Barbour, M.G., Keeler-Wolfand, T. and Schoenherr, A.A., Eds., Terrestrial Vegetation of California, 3rd Edition, University of California Press, Berkeley, 657-682.

[16] Masek, J.G., Vermote, E.F., Saleous, N., Wolfe, R., Hall, F.G., Huemmrich, F., Gao, F., Kutler, J. and Lim, T.K. (2006) A Landsat Surface Reflectance Data Set for North America, 1990-2000. Geoscience and Remote Sensing Letters, 3, 68-72. http://dx.doi.org/10.1109/LGRS.2005.857030

[17] Lentile, L., Holden, A., Smith, A., Falkowski, M., Hudak, A. and Morgan, P. (2006) Remote Sensing Techniques to Assess Active Fire Characteristics and Post-Fire Effects. International Journal of Wildland Fire, 15, 319-345. http://dx.doi.org/10.1071/WF05097

[18] van Wagtendonk, J.W. and Root, R.R. (2003) The Use of Multi-Temporal Landsat Normalized Difference Vegetation Index (NDVI) Data for Mapping Fuel Models in Yosemite National Park, USA. International Journal of Remote Sensing, 24, 1639-1651. http://dx.doi.org/10.1080/01431160210144679

[19] Lebassi, B., Gonzalez, J., Fabris, D., Maurer, E., Miller, N., Milesi, C., Switzer, P. and Bornstein, R. (2009) Observed 1970-2005 Cooling of Summer Daytime Temperatures in Coastal California. Journal of Climate, 22, 3558-3573. http://dx.doi.org/10.1175/2008JCLI2111.1

[20] Gelman, A. and Hill, J. (2007) Data Analysis Using Regression and Multilevel/Hierarchical Models. Cambridge University Press, New York.

[21] MacDonald, G.M. (2007) Severe and Sustained Drought in Southern California and the West: Present Conditions and Insights from the Past on Causes and Impacts. Quaternary International, 173, 87-100. http://dx.doi.org/10.1016/j.quaint.2007.03.012

[22] Seaber, P.R., Kapinos, F.P. and Knapp, G.L. (1987) Hydrologic Unit Maps. US Geological Survey Water-Supply Paper 2294, 63 p. 